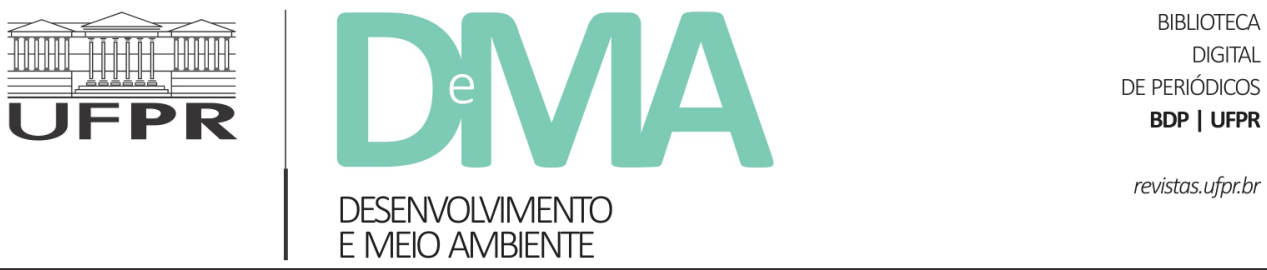

\title{
Geografia-Sul, uma proposta desde o Pensamento Ambiental latino-americano
}

\section{South-Geography, a proposal from Latin American environmental thinking}

\author{
Elisabete de Fátima Farias SILVA ${ }^{1 *}$, Diana Alexandra BERNAL ${ }^{1}$ \\ ${ }^{1}$ Pós-Graduação em Geografia, Universidade Estadual de Campinas (Unicamp), Campinas, SP, Brasil. \\ *E-mail de contato: lisafariasgeografia@gmail.com
}

Artigo recebido em 28 de abril de 2019, versão final aceita em 30 de julho de 2020, publicado em 3 de dezembro de 2020.

RESUMO: Emergente da terra e rompendo com os núcleos de sentido sujeito-objeto por sustentar a ciência moderna e a visão fragmentada e hierarquizada de um mundo universalizado, a produção ambiental-estética-filosófica da colombiana Ana Patricia Noguera de Echeverri nos incita a trilhar outros caminhos e a desdobrar uma geografia-Sul que brote e floresça do ethos Abya Yala. Aterrada pelo Pensamento Ambiental latino-americano, Noguera transborda uma geografia-Sul que emerge de nossa situação e circunstância. Um Sul não apenas em diferença a uma cultura do Norte, mas, sobretudo, um Sul que inverte, inventa, r-existe, transforma, habita nas fissuras, nos silêncios, às margens de um discurso único, universalizante e moderno.

Palavras-chave: descolonizar; transdisciplinar; Abya Yala; ethos Sul.

ABSTRACT: Emerging from the earth and breaking with the core of subject-object sense for sustaining the modern science and the fragmented and hierarchical vision of a universalized world, the environmental-aestheticphilosophical production of the colombian Ana Patricia Noguera de Echeverri encourages us to follow other paths and to unfold a South geography that sprouts and flourishes from the Abya Yala ethos. Landed by the latin american Enviromental Thinking, Noguera overflows a South-geography that emerges from our situation and circumstance. A South that is not only different from a culture of the North, but above all, a South that reverses, invents, r-exists, transforms, inhabits in the fissures, in the silences, on the margins of a single, universalizing and modern discourse.

Keywords: descolonize; transdisciplinary; Abya Yala; South ethos. 


\section{Introdução: raízes}

Interessadas pelo Pensamento Ambiental latino-americano (Ángel, 1990; 1996; 2003; Noguera, 2004; 2007a; 2007b; 2012b), encontramos neste campo teórico uma variada gama de discussão em diferentes projeções da relação sociedade-natureza. Emergente da terra e rompendo com os núcleos de sentido sujeito-objeto por sustentar a ciência moderna e a visão fragmentada e hierarquizada de um mundo universalizado, a produção ambiental-estética-filosófica da colombiana Ana Patricia Noguera nos incita a trilhar outros caminhos e a desdobrar uma geografia-Sul que brote e floresça do ethos Abya Yala.

A partir do Pensamento Ambiental colombiano, na figura de seu mestre Carlos Augusto Ángel Maya, Noguera trabalha os conceitos de geopoética (Pardo, 1991), corpo-terra e geopensamento, via reencantamento do mundo, tecendo laços estético-críticos que nos dão bases de um pensamento aterrado, vivo e vivido, voltado à experiência Sul, entendendo-nos como e com a terra.

A relação com a terra constitui o mais próprio de nossa humanidade, nosso ser húmus, humano. Conceber a terra nesta América Latina, por uma geografia-Sul, significa compreender o que nela fecunda, brota, floresce. Assim como o que nela falta, carece, finda. A terra, por sua vez, tem a capacidade de nos mostrar em quê e como a vida se multiplica, desdobra-se, amplia-se ou, ainda, em quais condições a vida se enfraquece, paralisa e extingue.

O Pensamento Ambiental Latino-americano por Augusto Ángel Maya e Ana Patricia Noguera é tecido em vias da vida e de todas as expressões e inspirações que dela advêm. Não é o humano que tem poder, privilégio ou primazia sobre a natureza. Não estamos fora, dentro, acima ou abaixo do ambiente, estamos nele, pois somos natureza, somos terra, água, ar e fogo e estamos implicados nessa trama da vida (Capra, 1998), sistêmica e complexa (Morin, 1994; 2008).

Para que a vida se faça presente nesta terra foi e é preciso cultivar, cultuar, cuidar, ser e fazer-se cultura: húmus da terra. Dessa relação natureza-cultura emerge o que nomeamos ambiente (Ángel, 1995; 1996) e é nessa tessitura que a crise ambiental vivenciada atualmente, tanto quanto a crise da ciência (Husserl, 1991), é entendida como uma crise cultural (Ángel, 1995). Essa chave abre importantes interpretações via Pensamento Ambiental latino-americano, as quais Noguera desencadeará ao longo de suas obras.

Para a filósofa (Noguera, 2007b), é, sobretudo, sem apartar natureza e cultura, que é possível pensar ambientalmente e dar vazão a esse corpo-terra que nos alimenta e que alimentamos, que está doente e que nos adoece, que faz guerra e está em guerra contra tudo e contra todos (Serres, 1991). Via diálogo poético, Noguera se nutre da arte, compreendendo-a no mais essencial dela como poiesis e esthesis, assim, bebe das obras de diversos(as) artistas que evocam a terra, como no caso de Frida Kahlo (Figura 1), reconhecida pintora mexicana, que nos motiva a entender como corpo-terra o emergir de uma geografia-Sul.

Por essas veias que se nutrem da terra, o Pensamento Ambiental latino-americano em Noguera se embrenha para reinventar os territórios, via compreensão outra do mundo em seu caráter epistêmico-poético-político na teia da complexidade dos modos de habitar. 


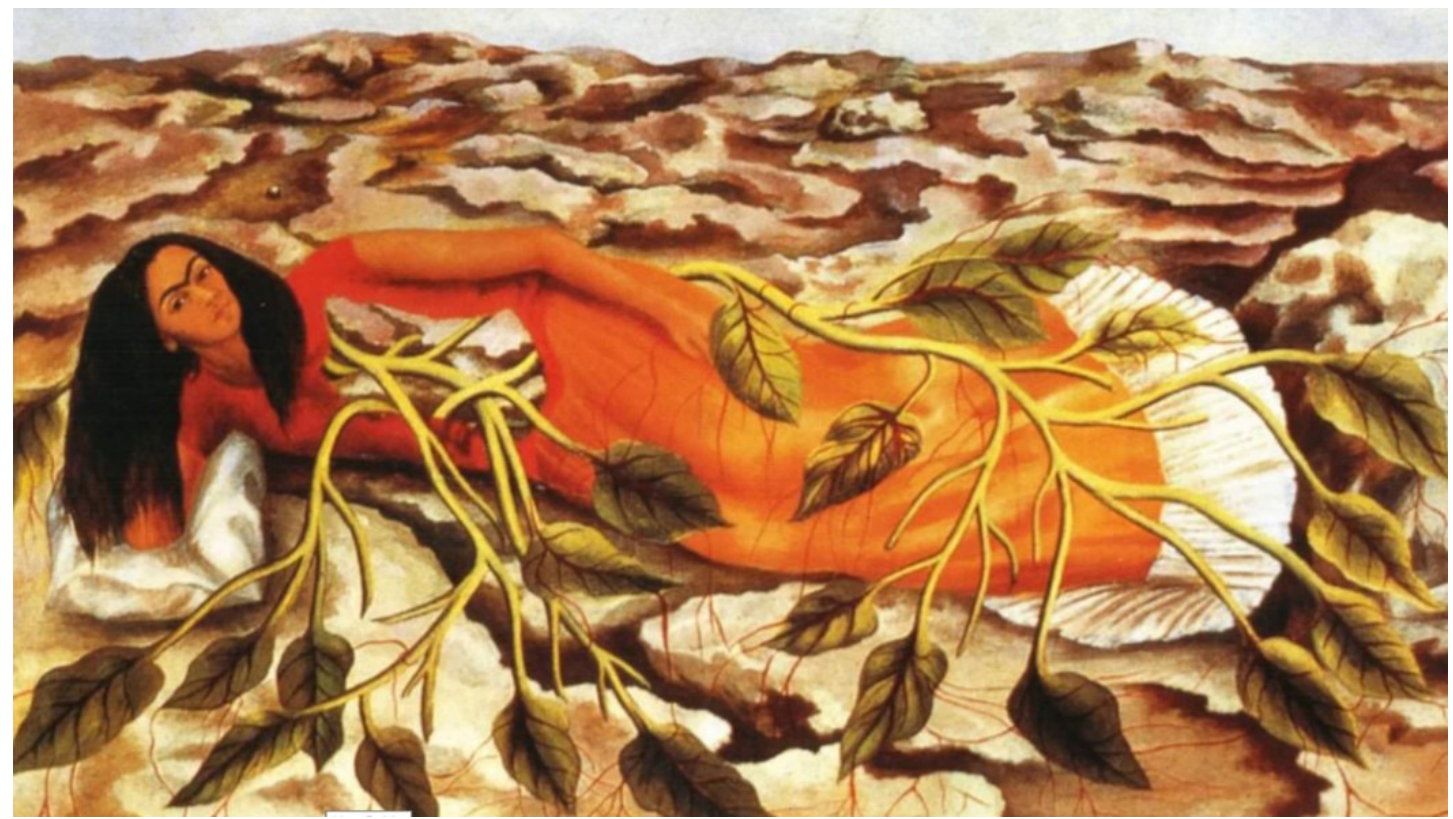

FIGURA 1 - "Raices", 1943, por Frida Kahlo.

FONTE: Disponível em: <https://www.fridakahlo.org/roots>. Menção em Noguera (2012b, p. 28).

Neste trabalho, buscaremos mais específicamente o que Noguera entende por geografia-Sul, a partir da leitura dos livros: "Escisión y reconciliación: movimiento autorreflexivo de la modernidad estética" (Noguera, 1998), "Educación estética y complejidad ambiental” (Noguera, 2000) "El reencantamiento del mundo" (Noguera, 2004), "Cuerpo-tierra: el enigma, el habitar, la vida, potencias de un pensamiento ambiental en clave del reencantamiento del mundo" (Noguera, 2012b) e artigos e capítulos de livros de sua autoria (Noguera, 2006; 2007a; 2007b; 2010; 2012a; 2015; 2016; Noguera \& Giraldo, 2017; Noguera \& Piñeda, 2009; 2011; 2014; 2017; Noguera \& Toro, 2016).

Para tanto, em 2. "Reflexões de uma filósofa colombiana: frutos em colheita", apresentare- mos o trabalho filosófico de Ana Patricia Noguera apontando autores e teorias base com os quais ela dialoga e constrói sua produção em consonância ao Pensamento Ambiental latino-americano, respectivamente, nos subitens 2.1. "Influências teóricas: adubo para florescer" e 2.2. "Conceitos-imagem em Noguera: laçar vida, ciências, artes e filosofias, pela integralidade da diferença, via discussão ética-estética". Por sua vez, em 3. "Geografia-Sul: emergência deste trato com a terra", adentraremos na tessitura argumentada pela autora dando especial atenção à trama que compõe esta geografia-Sul, destacando nos subitens 3.1. "Modos de habitar Sul: geografia-Sul em poiésis" e 3.2 "Reencantamento do mundo em tempos de penúria: uma sutura que emerge do Sul pela trama da vida", a articulação 
epistêmica tensionada por Noguera e sua proposta filosófica transdisciplinar e em sutura, respectivamente. Para então, em 4. "Considerações finais: desde o Sul e para além do Sul", pôr em relevo a fecundidade da filosofia ambiental de Noguera e do giro ético-estético-político inflexionado pelas contribuições de sentipensar este Sul e este corpo-terra diversa que somos.

\section{Reflexões de uma filósofa colombiana: frutos em colheita}

La invitación del Pensamiento Ambiental nuestro, es emergente de las voces de Abya Yala, en consonancia-disonancia con las voces de la tierra, es la comprensión de la lengua de la tierra (Noguera, 2012a, p. 321).

Ana Patricia Noguera de Echeverri, licenciada em Filosofia e Humanidades (1976, Universidad Santo Tomás/Colômbia), mestra em Filosofia (1992, Universidad Nacional de Colombia - sede Bogotá), doutora em Filosofia da Educação (1997, Universidade Estadual de Campinas/Brasil) e com pós-doutorado em Estética Ambiental Urbana (2001, Universidad de Barcelona/Espanha), é professora emérita aposentada pela Universidad Nacional de Colombia (UNAL), sede Manizales, com vínculo na pós-graduação da mesma instituição e coordenadora e cofundadora do grupo de pesquisa "Pensamiento Ambiental", fundado em 1993, no departamento de Ciências Humanas da UNAL.

Noguera constrói uma filosofia ambiental a partir do Pensamento Ambiental latino-americano, que para ela é uma construção epistêmico-ético-estética ambiental que busca a compreensão do "dominio y explotación de las tramas de la vida" (Noguera, 2006, p. 2). A vasta publicação da pesquisadora nessa temática (Noguera, 1998; 2000; 2004; 2006; 2007a; 2007b; 2012b) sustenta seu papel de destaque na produção da interface Pensamento Ambiental, fenomenologia e interdisciplinaridade.

Atualmente coordenado por Noguera, o grupo de pesquisa "Pensamiento Ambiental", na UNAL, é um relevante centro de pesquisas latino-americano. Organizado em 1989, formalizou-se em 1993, sob a coordenação do historiador Carlos Augusto Ángel Maya, que desde fins da década de 1970 já vinha dedicando-se às reflexões ambientais. Após seu falecimento, em 2010, Noguera, que acompanhava Ángel desde 1987, assumiu a coordenação do grupo que ajudou a fundar, dando forte ênfase ao sentido estético-político do pensamento ambiental - tensionando a própria filosofia ambiental realizada até então.

Lo estético dejó de ser un pensamiento reducido al problema de lo bello, para convertirse en maneras de habitar, crear, co-crear, transformar las texturas de la tierra-naturaleza-vida, por los cuerpos vivos como emergencias estéticas de la tierra. Lo estético se amplificó, se expandió al sentir de la vida, y la vida como sentir (Noguera \& Piñeda, 2017, p. 355).

A noção ampliada de estética reverbera nos trabalhos de Noguera, desde a concepção de poiesis e esthesis, em consonância com os conceitos-imagem habitar e vida. Em seus textos é expressa uma tessitura prenhe de cores, sons e cheiros de um ethos Abya Yala. Várias de suas obras combinam texto escrito com a descrição e discussão de conceitos-imagem, tecidas com pinturas, esculturas, letras de canções, mitos, poesias. Essas outras linguagens 
não são exemplos, nem tão pouco representações e/ou ilustrações da produção acadêmico-cientifica e da discussão filosófica-ambiental, pois elas já são em si uma expressão estética da terra. Em sua potência expressiva, diferentes linguagens trazem ao Pensamento Ambiental em Noguera uma estética Sul (Noguera, 1998; 2004; 2012b).

O grupo "Pensamiento Ambiental' tem uma ampla produção nessas mais de duas décadas de pesquisa, versando sobre temas como a ética, estética, epistemologia, educação e filosofia ambiental. As investigações reverberam no campo das humanidades e das relações entre pensamento e terra, com propostas investigativas densas que envolvem ecossistema-cultura, corpo-mundo-da-vida-simbólico-biótico-afetivo e corpo-terra, pela chave interpretativa da estética e do pensamento complexo (Ángel, 1996; Noguera, 2004; 2017; Mesa, 2010; Chacón, 2011; Merchancano-Benavides, 2015; Bernal Arias, 2015; Piñeda, 2015; entre outros).

Noguera enfatiza' que "son pocas las instituciones académicas que se dedican a la construcción de pensamiento ambiental". Destas, destacam-se México, Colômbia, Argentina, Chile, Venezuela, Cuba e Brasil, que se colocam a pensar a América Latina a partir das questões ambientais, em suas diversas facetas e projeções teórico-políticas. $\mathrm{Na}$ consolidação histórica deste campo, o grupo "Pensamiento Ambiental" é a primeira escola na Colômbia, tanto em produção de conhecimento como em criação de novas linguagens, afirma a filósofa.

Nesse quadro, Noguera entende que "La filosofía ambiental no es una filosofía ni del sujeto, ni del objeto; ni de la dialéctica sujeto/objeto" - pos- tura que implica, inclusive, na estrutura textual de sua produção filosófica, tornando-a mais fluida e menos cartesiana, segmentada e linear. Para romper com as divisões modernas, "la filosofía ambiental debe continuar con la propuesta fenomenológica de difuminación del sujeto y del objeto, como polos que se oponen, para comprender el mundo de la vida como trama, tejido y red de vida" (Noguera \& Piñeda, 2009, p. 262). E compreender o mundo da vida como trama e rede consiste em exercitar a sutura, em co-ligação, dissolução, tensão (Noguera, 2010; 2016) dos conhecimentos e dos diversos modos de habitar a terra, consiste em colocar-se, articular e relacionar os fios que nos formam e que formamos: dos trabalhos em campo à escrita científica, do pensar ambiental ao ser ambiental, do pensar a arte e a filosofia e ciência ao ser com a arte, com a filosofia e com a ciência, com a vida. Por isso, além de fazer a proposição filosófica de um pensamento outro, Noguera se vale de um escrever aterrado e poético.

Em "Educación estética y complejidad ambiental”, por exemplo, Noguera (2000) faz uma interessante incursão desde suas experiências no Ensino Superior relacionada às artes, filosofia, ciência e educação, como das coordenações da área de Teoria e História da Arquitetura, na Universidade Nacional da Colômbia: "Por mi formación en el campo del arte - especialmente en la música y en la pintura - en el campo de la filosofía moderna y en el pensamiento ambiental, he realizado un trabajo teórico apoyado en los diferentes momentos de mi práctica pedagógica” (Noguera, 2000, p. 7).

Ao longo de sua produção acadêmica, Noguera plantou sementes capazes de combinar ciência,

${ }^{1}$ Site ColCiencias, banco de dados de professores/pesquisadores colombianos. Informações disponíveis em: $<$ http://scienti.colciencias.gov. co:8085/gruplac/jsp/visualiza/visualizagr.jsp? nro $=00000000000945>$ 
filosofia e arte, inter e transdisciplinarmente, em sutura. Sem perder a potência de um compromisso crítico e reflexivo, elaborado com extrema leveza por conceitos-imagem que provocam o reencantamento do mundo, inspirando-se no sentipensar (Escobar, 2014) a trama da vida desde essa terra diversas que somos.

Justamente pela proposta da autora, suas obras não destroem o que aqui (ciência/Ocidente/ presente) se dá, argumentando que a solução para os problemas vividos se dará em outro momento (futuro salvacionista). Noguera nos incita a entender-nos terra, co-ligados, dissolvidos, tensionados e, assim, sentir essa geografia-Sul que já somos e podemos produzir/ser/viver com mais intensidade ao perceber quais discursos não nos pertencem e não condizem com essa terra que somos. A filósofa ainda nos provoca a pensar quais discursos queremos produzir e como a terra pode afetar e ser afetada por nossa produção acadêmica.

Nessas vias, o Pensamento Ambiental por ela trabalhado, desde Ángel Maya, não centraliza e justifica o desenvolvimento sustentável baseado na dicotomia homem-natureza e na globalização, tal como desdobrado por vários centros acadêmico-científicos desde a Primeira Conferência Mundial do Clube de Roma, em 1968, quando esses assuntos começaram a ser pautados a partir da ideia de "limite" da natureza e "conforto" da vida humana (Ángel, 1995; Noguera \& Piñeda, 2009). Essas questões, que apareceram explicitadas na consagrada obra "Os limites do crescimento", de 1972, elaborada pelo Massachusetts Institute of technology (MIT), foram ainda mais fundamentadas e difundidas mundialmente pelas demais conferências internacionais que formalizaram o histórico de reflexão das ques- tões ambientais, como as em Estocolmo (1972), Rio de Janeiro (1992 e 2012) e Johanesburgo (2002).

A despeito da história da constituição desse campo teórico, Noguera (2006, p. 7) denuncia que, nessa mesma esteira, a produção acadêmico-científica também está atrelada a um ambientalismo superficial: "primando una visión mecanicista de la naturaleza y de la sociedad, donde las parcelas del conocimiento disciplinar no han podido ser superadas. Aunque la realidad es profundamente compleja, nuestro pensamiento permanece en la linealidad". Todavia, o colombiano Augusto Ángel Maya, desde a década de 1990, já apontava que o Pensamento Ambiental na América Latina vinha caminhando por outras trilhas que não necessariamente as pegadas deixadas pelos países do primeiro mundo, os quais têm outras definições e interesses quanto às noções de ambiente, desenvolvimento, território e recurso.

En América Latina ha empezado a surgir un pensamiento ambiental independiente, que se manifiesta en el modelo latinoamericano construido desde el Centro Bariloche, en las conclusiones del Seminario de Universidad y Medio Ambiente, celebrado en Bogotá en 1985 y en diferentes artículos y libros que se han venido publicando en los últimos años. Las tendencias, sin embargo, no asumen todas ellas una posición independiente. Algunos autores siguen muy de cerca las corrientes europeas, otros estimulan un pensamiento autónomo (Ángel, 1996, p. 108-109).

Inclusive em "El reto de la vida", Ángel Maya (1996), além de detalhar seu modelo conceitual ecossistema-cultura, tão fértil para um pensamento aterrado, ainda traz listas de orientação bibliográfica ("Explicações desde as ciências naturais", "Explicações ambientais desde as ciências do homem”, 
"Economia, política, desenvolvimento e meio ambiente" e "Pensamento ambiental na América Latina"), em referência ao estado da arte da produção científico-filosófica até aquele momento, com a indicação de uma bibliografia rica, diversa e potente, já na década de 1980, para pensar ambientalmente o Sul que somos.

Adjetivar o Pensamento Ambiental com "latino-americano" e Pensamento Ambiental "Sul" marca a necessidade de pontuar que, além de uma produção nesta América, as reverberações desse campo se projetam para esta América. Desdobramento de um sentipensar desde nossa constituição para o que significa ambiental, sem a arrogância de torná-lo um pensamento único e universal. Por isso mesmo, aqui também brotam várias correntes de Pensamento Ambiental, pois somos terra-diversa, alerta-nos Noguera (2004).

\subsection{Influências teóricas: adubo para florescer}

A respeito da diversidade, as obras de Noguera e Ángel Maya nos mostram que é possível valer-se de pensadores europeus sem, contudo, trabalhar com uma visão eurocêntrica de ciência e sociedade. Noguera não rejeita as contribuições do mundo da vida e crise da ciência elaborados por Husserl, do habitar heideggeriano, ou ainda da discussão deleuziana de rizoma, do pensamento complexo de Edgard Morin, da ação comunicativa de Habermas, do contrato natural de Serres e, mesmo, da base fenomenológica nascida e ampliada em terras alemãs e francesas (Figura 2).

Entre esses pensadores europeus, ainda tem um holandês de grande peso para Noguera. Baruch
Spinoza foi responsável por uma outra guinada na filosofia, tanto na ética, quanto na relação Deus-natureza e no conceito de multitudo, dos quais Noguera tem especial atenção:

Spinoza es el primer ecólogo de la Modernidad y es el filósofo que se atreve a pensar en el ser como multitudo o todo-múltiple. Con él comienza un tipo de pensar complejo que es ocultado por la razón lineal y analítica, porque es un tipo de pensar donde el individuo no tiene cabida. A fin de cuentas, el individuo es una construcción necesaria para legalizar la propiedad privada, como un derecho burgués que nace, precisamente, del clímax del egocentrismo; el concepto de multitudo o todo múltiple sólo es posible a partir de la imposibilidad de la no relación. Es decir, el ser es relación, conexión, no individuo. (Noguera \& Piñeda, 2009, p. 268).

Em diálogo com esses autores, Noguera cria uma teia teórica capaz de adubar um Pensamento Ambiental Latino-americano que sente e pensa essa terra em laço com um viver-Sul.

Assim como são demais nutritivos para o Pensamento Ambiental florescido em Noguera alguns autores latino-americanos, como o filósofo colombiano Guillermo Hoyos Vásquez (orientador de Noguera em Filosofia Moderna - Noguera, 1998), o economista e sociólogo mexicano Enrique Leff, os colombianos Orlando Fals Borda (sociólogo) e Arturo Escobar (antropólogo), os biólogos chilenos Humberto Maturana e Francisco Varela, o filósofo argentino Rodolfo Kusch e, também, o geógrafo brasileiro Carlos Walter Porto-Gonçalves. Com os quais a filósofa compõe um belo e diferencial quadro epistêmico ao Sul (Figura 2).

Expressões artísticas, como as obras de Van Gogh, Edvard Munch, Oswaldo Guayasamín e Frida Kahlo também são constantes na produção 
acadêmica de Noguera. Com reflexões poéticas de Hölderling e Rilke e canções de Mercedes Sosa e Astor Piazolla, a colombiana tece sua filosofia epistêmico-estética junto às artes de um modo muito próprio.

Assim, Noguera nos inspira a produzir um Pensamento Ambiental que não esteja à parte $\mathrm{e}$ nem se esmoreça perante outros lugares de fala, conhecimentos diversos e linguagens distintas. É um convite para se alimentar desde essa terra, por teorias e autores que nos valham para nos autoconhecermos e direcionarmo-nos sem, todavia, excluir e/ou ignorar o conhecimento de outras terras. Nesse processo de trama, a fagocitoção é um manifesto já reclamado em 1922, no Brasil, e por Kusch em sua América Profunda, de 1962.

Para a filósofa, a razão dialógica reconhece a diferença e, direcionando-se à alteridade, o Pensamento Ambiental em Noguera enlaça e deseja a sutura entre vida e pensamento - co-ligar, dissol- ver, tensionar (Noguera, 2010). Compreendendo as diferenças, mas de modo algum eliminando-as, ignorando-as, submetendo-as a moldes pré-estabelecidos que dividem, separam, amputam ou invisibilizam, homogeneízam, generalizam (Noguera, 1998; 2004). A geografia-Sul sugerida pela colombiana segue esse desafio de entender-nos, de ouvir-nos e pensar-nos, sem para isso ignorar o que já fora produzido, tanto cientificamente quanto em outras racionalidades ainda diminuídas pela lógica universalista-moderna-ocidental.

No artigo "Pensamiento ambiental sur en tiempos de penuria", por exemplo, Noguera (2015, p. 16) enfatiza que Augusto Ángel, Michel Serres e Edgar Morin, três pensadores ambientais, filósofos da dissolução da divisão sociedade e natureza, "nos retan a pensar distinto, a impugnar lo políticamente correcto, a retomar el cuerpo-tierra que somos, a re-encantar el mundo, en clave de acciones poético-políticas, que nos permitan habitar poéticamente".

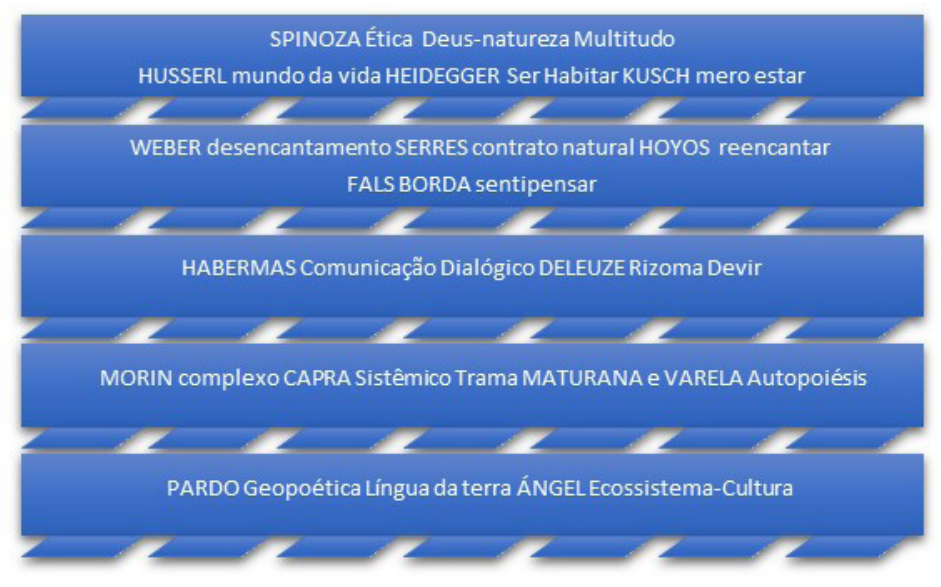

FIGURA 2 - Diálogo fértil: principais autores e alguns de seus conceitos que dão base à Noguera FONTE: Organização das autoras 
Nem por isso, a produção de Noguera tende a ser eurocêntrica por se valer autores europeus, tanto quanto é inválido julgar que, se ela usasse exclusivamente autores latino-americanos, sua produção seria um pensamento originalmente vinculado e projetado ao Sul.

É assim, tecendo junto, em comunicação dialógica, que Noguera produz e nos convida a produzir. No precioso artigo "Pensamiento Ambiental complejo y gestión del riesgo: una propuesta epistémico-ético-estética" (2006), a filósofa aborda alguns autores latino-americanos notáveis nesse campo teórico que trabalham a ética ambiental em direção às teorias da complexidade. Dos quais ela destaca por afinidade teórica: Augusto Ángel Maya (ética como desfrute da vida), Daniel Vidart (ética ambiental sistêmica), Guillermo Hoyos Vázquez (ética comunicativa), Julio Carrizoza Umaña (ética-estética ambiental complexa como caminho para a Paz), Arturo Escobar (ética ambiental desde uma antropologia dos lugares) e Enrique Leff (ética ambiental como uma nova racionalidade). Nas palavras de Noguera (2006, p. 18):

Las propuestas de Arturo Escobar, Augusto Ángel, Enrique Leff y Julio Carrizosa, se construyen sobre la necesidad de transformar el edificio de las prácticas culturales de la modernidad industrial, tecnológica, científica y social, que se han caracterizado por la homogenización de la diversidad, una negación del otro y de lo otro, y una actitud de dominio sobre la naturaleza ecosistémica y sobre las culturas no modernizadas. Muestran también la necesidad de resignificar y valorar las prácticas de otras culturas, donde la integralidad entre lo mítico, lo simbólico, y los imaginarios propios de cada cultura, con la naturaleza ecosistémica, permitan el diálogo de saberes tan necesario dentro de nuestra cultura marcada por una profunda incapacidad de escuchar y respetar al otro.
2.2. Conceitos-imagem em Noguera:

laçar vida, ciências, artes e filosofias, pela integralidade da diferença, via discussão ética-estética

Valendo-se dessa terra fértil das influências teóricas citadas acima, Noguera se lança no Pensamento Ambiental-Outro, como traçado em seu artigo "Cuerpo-Tierra: epojé, disolución humano-naturaleza y nuevas geografias-sur" (Noguera $\&$ Piñeda, 2014). Contudo, a trama desenhada por Noguera na elaboração de um Pensamento Ambiental-Outro já é presente desde suas primeiras produções, como em "Escisión y reconciliación: movimiento autorreflexivo de la modernidade estética", publicado em 1998 - como requisito para professora titular emérita no Departamento de Ciências Humanas, UNAL. Neste trabalho, a autora argumenta quanto à reflexão do sentido da arte emaranhado à vida como campo dinâmico de todas as culturas. A partir de uma visada pós-moderna, “Escisión y reconciliación” já guarda importantes pontes que Noguera atravessaria ao longo de suas obras, como o esforço de laçar vida, ciências, artes, saberes e filosofias, pela integralidade da diferença, via discussão ética-estética.

Nessa reconciliação teórica do que é ambiental, o conceito husserliano de mundo da vida ( $L e$ benswelt) é bem trabalhado por Noguera, como uma "estructura vital de la reconciliación" da redução do mundo para fins da razão instrumental provocado e pregado pela modernidade (Noguera, 1998, p. 17).

Pelo conjunto da produção desta filósofa colombiana, interpretamos que ela frutifica uma fenomenologia ao Sul, na qual cultiva outras reflexões a partir desta terra que somos. Reconhecendo que 
a fenomenologia é uma das primeiras possibilidades teóricas de dissolução dos polos dicotômicos concebidos modernamente, como sujeito e objeto, Noguera (2007b, p. 28) ainda destaca que "En nuestros intentos de construcción de una ética integral compleja, habíamos encontrado en la Fenomenología de la corporeidad, un camino de integración en las diferencias, entre el humano y las formas de la naturaleza ecosistémica", a qual se vale para elaborar seu Pensamento Ambiental em vias do mundo-biótico-de-vida-simbólico.

Consolidada nos últimos anos na Geografia brasileira, a abordagem fenomenológica cresceu em reconhecimento e se apresenta enquanto campo consolidado e ativo. Marandola Jr. (2013, p. 56) contextualiza que "Ao invés de uma subcorrente do pensamento geográfico, apresenta-se como esteio metodológico e epistemológico (às vezes até ontológico), para o enfrentamento de temáticas variadas". Entre geografia-Sul e Pensamento Ambiental, a fenomenologia em Noguera é encarada como caminho teórico-metodológico para compreender-se um modo outro latino-americano de viver a terra:

El Pensamiento Ambiental-Otro, inspirado en la tierra exuberante que somos a pesar de Europa, propone hacer una epojé del pensamiento moderno: poner entre paréntesis la racionalidad que ha reducido los cuerpos vivos a cuerpos amputados de la tierra (Noguera; Muñoz, 2014, P.21).

Esse amputamento, corte, divisão dos corpos e da própria ciência ocidental-moderna-universalista em crise (Husserl, 1991) é a perda da integridade que "han marcado la esencia de la política, la ética, la educación y la pedagogía modernas". A despeito disso é que o Pensamento Ambiental em Noguera busca a dissolução dos polos consagrados nos discurso lineares, causais e desenvolvimentistas produzidos pelos países de primeiro mundo quanto à natureza: "Mirada así la naturaleza, pasa ella a ser pensada no por la posibilidad esencial que ella tiene de ser, sino por lo que es desde la perspectiva de la racionalidad: objeto de explicación lógico-matemático" (Noguera, 1998, p. 33). E isso nos provoca a pensar que a geografia-Sul é possível em vias da co-ligação da trama da vida, entendendo-nos natureza, com e como corpo-terra: "Una filosofía ambiental emergente de América Latina tendría que ser una filosofía espacial, geológica, territorial, donde la potente trama de vida que constituye las geografías latinoamericanas, es la casa del ser y de la cual emerge el ser" (Noguera, 2010, p. 190).

\section{Geografia-Sul: emergência deste trato com a terra}

A geografia-Sul em Noguera de modo algum trata de uma questão disciplinar, pois é uma mirada desde a terra à nossa relação com ela, nosso trato, contato e afeto. E esta geografia-Sul é expressa há milhares de anos em éticas e estéticas outras e, por isso, também carece de epistemologias próprias que desvelem as tramas da vida que aqui são tecidas em co-ligação, dissolução e tensão com os diversos corpos-terra que somos.

Destacar a geografia-Sul à discussão ambiental é um chamado ao pensamento aterrado, vivo e vivido, que compreende o histórico do fazer científico-filosófico a partir do corpo-mundo-da-vida-simbólico-biótico-afetivo. E isso não se trata de um essencialismo particular (Marandola Jr., 2013), mas de partir e voltar-se à experiência que nos faz 
ser-e-estar em um Sul não apenas distinto de uma cultura do Norte, mas, sobretudo, um Sul múltiplo com capacidades férteis para pensar e propor de acordo com as necessidades que brotam desta terra que somos.

O livro "Hojas de sol en la victoria regia: emergencias de un Pensamiento Ambiental Alternativo en América Latina", organizado por Noguera (2007b), conta com um artigo de sua autoria, no qual ela tece com mais detalhes uma filosofia ambiental em vias de uma geografia-Sul. Noguera contextualiza que a compreensão do mundo da vida cotidiana emerge de um pensamento espacial, não apenas na dimensão histórico-temporal tal como a ciência e a filosofia vinham prestando-se a fazer: "La filosofía moderna había estado atrapada en el Tiempo, en un devenir o un provenir; una sucesividad, una teleología, un útopos, una historicidad que sin espacio-lugar, mantuvo su condición metafísica". Provocada pela fenomenologia husserliana, o mundo da vida nos incita ao regresso do pensamento à casa (oikos), geografando uma filosofia aterrada que começa a ser possível "a partir de una ecologización del pensar y un pensar ecológico, correlativo, auto-eco-organizativo, georreferencial, en estratos geológicos; un pensar corpóreo, huella; un pensar-habitar, un pensar-tierra, pensar-cultivo" (Noguera, 2007b, p. 29).

Se a filosofia do tempo causal e finalista se concentra em objetivos, metas e degraus que são necessários atingir, a filosofia do espaço se dedica a construir, suturar o fissurado, pôr em diálogo o que fora silenciado, aterrar o vivido múltiplo e em movimento, "ir más allá del sujeto y/o/vs el objeto, para pensar la vida como un todo múltiple, tejido potente, estético, haciéndose". A oiko-filosofia exige pensar o já pensado via filosofia do tempo e o ainda não pensado, todavia desde os territórios que marcam e são marcados pelo Habitar-Sul. Uma geografia da filosofia não exclui, sobremaneira, a história, pois "la geografía es tiempo-cuenca, tiempo-meseta, tiempo-valle, tiempo-espacio-lugar-tiempo, en una coligación bucléica virtuosa que configura estrato-huella, la una como emergencia histórica del otro" (Noguera, 2007b, p. 30).

O convite ao processo de descolonização da filosofia e da construção de uma filosofia ambiental que brote e floresça com estas viradas, alimentadas por uma geografia-Sul, implica no abandono do paradigma e na emergência de uma filosofia enigma (Noguera, 2007a), em que as relações de autopoiésis da ontologia, epistemologia, da ética e da estética configurem uma trama que permita a complexidade da vida em movimento desde corpo-terra.

A filosofia ambiental complexa é uma filosofia aterrada que fecunda e convida uma geografia-Sul a lançar-se em territórios-espaços-lugares-paisagens com tempos diversos tecidos pela trama da vida. Onde e quando espaço-tempo se mostram para além do cronológico, oficial, linear, progressista, geométrico, numérico, constante.

Deste Sul, irrompe e nasce uma cartografia outra que marca a singularidade e diferença de um filosofar e geografar essa trama que nos compõe e que necessita de um pensar-saber-produzir desde nossos laços:

Si el tiempo lineal y teleológico de la Modernidad atrapó todos los tiempos y espacios de la diversidad de mundos de vida, en un solo tiempo: el de la historia unificadora y simplificadora, de nuestras reflexiones filosóficas ambientales, emerge un concepto de ser territorio-espacio-lugar. Encontramos necesaria una geografización de nuestro tiempo, ese que da qué pensar, en su singularidad y diferencia. Los conceptos ya no son definiciones discursivas, sino mapas, donde 
cuencas, valles, mesetas, montañas, ríos y mares, se entretejen bucléicamente en tramas-redes-urdimbres-tejido (Noguera, 2007b, p. 47).

Geografia-Sul consiste na beleza de nossas matas, nossos rios, nossos relevos, nossa fauna, nossa imensa e variada geologia e geomorfologia. Consiste também em nosso campo e nossa cidade, nossas comunidades originárias, quilombolas e ribeirinhas, nossos interiores pouco povoados e nossas grandes metrópoles. Geografia-Sul consiste em nossos desastres ambientais, nossa grande população miserável, nossos altos índices de violência e analfabetismo, nossa demasiada exploração e desdém com a bio-sócio-diversidade que nos constitui. É a base, o chão, a tela de que nos compomos e que compõe a vida enlaçando ecossistema-cultura.

\subsection{Modos de habitar Sul: geografia-Sul em poiésis}

Antes de cunhar geografia-Sul e lançar-se a desdobrar esse enigma, Noguera já caminhava pelo Habitar-Sul via ethos Abya Yala. Habitar é pensado por ela a partir de Heidegger, contudo, ao considerar o conceito elaborado pelo alemão, que envolve a relação existencial com a terra, como morada do homem e do Ser, a filósofa colombiana desdobra essa reflexão ao questionar quem é esse homem e o Ser a que nos referimos, desde a perspectiva do Pensamento Ambiental latino-americano.

Nesta leitura diferencial é que Noguera (2015, p. 2) abordará o habitar que abriga "ser-estar-Sul": "un ethos originario, una variedad de maneras de habitar, que hacen del ethos un habitar que permita incontables variedades del habitar, un habitar en el permanecer $[\ldots]$..."

Já em suas primeiras obras percebemos que, mesmo trabalhando com autores europeus, Noguera faz uma leitura latino-americana das discussões filosófico-ambientais à luz da sua realidade vivida. Ao desenvolver Habitar-Sul, por exemplo, Noguera transita entre as obras heideggerianas, husserlianas e, mais recentemente, como em "Pensamiento Sur en tiempos de penuria" (Noguera, 2015), articula o pensamento do argentino Rodolf Kusch também, sem perder sua própria produção fortemente estética vinculando a geopoética dos povos originários que habitam esta terra em dança, música, arquitetura, sabores e saberes.

A ligação epistemológica de ser(Heidegger) e estar (Kusch) voltado ao Sul, por Noguera (2015), lembra-nos o modelo conceitual ecossistema-cultura proposto por Ángel Maya (1996), até porque o Pensamento Ambiental proposto por Noguera é de sutura (Noguera, 2004), e a filósofa considera Ángel como seu grande maestro.

Emergente dessa tensão e tecida na sutura corpo-terra, Habitar-Sul segue o ritmo da vida que pulsa desta terra. Habitar-Sul rompe orifícios da terra, do mar, do vento, das flautas indígenas e tambores afro-latinos, materializando sequelas e sequestros r-existindo ao silenciamento:

Las cuerdas de la guitarra, sus acordes, sus silencios, la voz de los cantores, emergen de las cenizas de la guerra-sur, también sin tregua y en medio de esas guerras: invasiones del norte, del dolor de no ser lo que se quiere ser, emerge la vida clamando por un habitar poético (Noguera, 2016, p. 94-95). 
Em ritmo, a vida pulsa uma língua da terra expressando um Habitar-Sul, um ethos Abya Yala. Lembrando que Abya Yala é um vocábulo dos Cunas da Costa Rica, Panamá e Colômbia e expressa dois significados que dialogam e são dependentes: "el buen vivir" e "tierra generosa, prodigiosa, en florecimiento" (Noguera, 2016, p. 78). Para Noguera, essas duas definições são a nomeação da simbiose com a terra que reverbera no próprio ethos-Sul de um pensamento que se faz terra, em terra, sendo a terra pensamento - o modo de Bem-Viver se dá por e com esta terra abundante, generosa, provedora, fértil.

Este pensamento-terra via ethos-Sul nos povoa face à descolonização de universalismos, purismos, dominações e superioridades, entre outras amarras que podam identidades múltiplas, alteridades e diferenças (Noguera, 1998) em florescimento desta terra diversa que somos.

No Pensamento Ambiental Latino-americano, esse ethos-Sul não necessita do adjetivo ambiental porque seu modo de viver a terra interligado em teias de sentidos já abarca tudo o que o conceito ambiental pode representar. Ethos-Sul é ethos Abya Yala dos povos originários que aqui semeiam, plantam e colhem a vida nesta terra em Bem-Viver (Noguera, 2012a; 2012b). Expresso em contato, no trato, no manuseio de como vivemos, em "rasguñar la tierra", essas geografias poéticas desde o Sul são propostas educativas em vias da vida, livre do domínio e exploração (Noguera, 2000). Nessa teia, não há espaço para um Pensamento Ambiental centrado nos recursos naturais, no desenvolvimento sustentável ou no indivíduo - como prega as preocupações ambientalistas do Norte e que, muitas das vezes, reproduzimos separando a natureza que somos em recurso água, recurso solo, recurso atmosfera, recurso energia....

Noguera ressalta que, mesmo que as vozes dos povos-Sul sigam sendo caladas, inclusive por nós mesmos, muito desse ethos Abya Yala ressoa em nós. Mesmo nas grandes cidades latino-americanas, mesmo com os processos de urbanização e industrialização crescentes, planificadores e importados com a promessa do desenvolvimento, podemos perceber que o Habitar-Sul nos constitui em nosso modo de ser-estar.

\subsection{Reencantamento do mundo em tempos de penúria: uma sutura que emerge do Sul pela trama da vida}

Na produção filosófica de Noguera, ela sempre nos presenteia com obras de cantores, pintores e escritores que nos lembram desse ethos Abya Yala, pois "son los poetas latinoamericanos quienes nos enseñan también a habitar la tierra poéticamente" (Noguera \& Piñeda, 2011, p. 296). É o que Ana Patricia Noguera, junto ao cientista social colombiano Omar Felipe Giraldo desenham com mais profundidade no artigo "¿Para qué poetas en tiempos de extractivismo ambiental?" - publicado na interessante obra "Ecología política latinoamericana: pensamiento crítico, diferencia latinoamericana y rearticulación epistémica” (2017), pela rede virtual do CLACSO, Consejo Latinoamericano de Ciencias Sociales - referência na publicação científica no campo do Pensamento Ambiental e da Ecologia política, entre outros campos. É, também, com esses poetas que nos lembramos dessa terra que somos e percebemos no som, no paladar, no trato com os outros, nas paisagens e arranjos territoriais 
a intensidade desse ethos-Sul e a latência de uma geografia-Sul.

Em Noguera \& Giraldo (2017), as fotografias do brasileiro Sebastião Salgado são apontadas como importante fonte de registro e inspiração para o desdobramento de um pensamento que parte deste Sul. Via arte, os registros disparam reflexões acerca da terra que somos, produto e produtora de imensas desigualdades.

As guerras e conflitos encontram guarida na cobiçada América Latina (Piñeda, 2015; Noguera, 2016), cartografando uma geografia-Sul de violência, corrupção e exploração que se espalham como ervas daninhas abafando um ethos Abya Yala originário, coletivo e aterrado. Noguera (2004; 2007a; 2012a; 2012b; 2017) traz essas mazelas tão presentes no cotidiano latino-americano por tantas formas e que tornaram a relação com a terra trágica e dolorosa: corpo-terra que grita a fome mesmo com os campos cheios - de monocultivos para exportação; que grita a sede mesmo com abundância de água - contaminada e extorquida pelas grandes indústrias; que grita o assalto dos minérios, o descaso com a justiça ambiental e a falta de memória de um passado próximo colonial e colonizador ainda tão atuais.

O Pensamento Ambiental em Noguera e sua reflexão de uma geografia-Sul não ignora as dores, mazelas e a podridão que perfaz o mundo da vida desta América em sua diversidade e desigualdade, todavia nos atenta para laçar o reencantamento do mundo nesses tempos de penúria - essa penúria que não, necessariamente, existe pela escassez de bens, pois Abya Yala terra rica nos dá em abundância, mas que, pela gestão moderna centralizadora e cumulativa dos territórios e da própria vida, impedem um florescimento das potências desta América.
O reencantamento do mundo (Noguera, 2004) se alimenta da necessidade de voltarmo-nos a sentir e pensar em, com e como terra. Pelo mundo da vida cotidiana, como elabora Gómez Heras, Noguera mostra que há de se partir dos corpos - todos os corpos - e de reencantar a trama dessa geografia-Sul da vida que aqui se dá: "Cada piedra, cada planta, cada animal, cada palabra, cada pensamiento, son cuerpo hecho de la tierra, por la tierra, sobre la tierra y bajo la tierra" (Noguera, 2014, p. 24) e que nos constitui para além da pobreza, miséria, desigualdade, violência e corrupção.

Assim, faz-se urgente des-ocidentalizar os estudos sobre a vida para desvelar suas emergências Sul. Pensar planetariamente, mas desde a singularidade dos lugares e da diversidade que somos. Como diz Noguera (2004, 2012b), amparada por outros pensadores ambientais, é preciso descer dos céus da metafísica para compreender-nos em, de e feitos de terra, corpos-terra, assumindo uma posição de afeto e respeito à terra-natureza-vida em todas as dimensões em que ela se apresenta (Noguera \& Toro, 2016), e isso perpassa a política, a ética, a estética, a educação e o fazer cientifico-filosófico Sul.

A geografia-Sul que filosofa Ana Patricia Noguera é complexa, sistêmica, poética. É, também, política, ética, livre, diversa. E nas maneiras de cultivar, conviver, cultuar a terra, uma geografia-Sul nasce em poiésis, em trabalho, labor, mirando um pensamento crítico a todos os tipos de colonialismos, domínio e exploração. Inspirando-nos a fortalecer, sobretudo a nós mesmos, a relação existencial geográfica com essa terra que somos, que estamos e que desejamos com-viver.

Sul é uma "palabra hermosa" que também expressa "desarraigo, tristeza y soledad, es una palabra-lugar ritual", diz-nos Noguera (2012b, p. 
92). Habitar-Sul é habitar as margens, em enigma, é respeitar o tempo não dito no silêncio da razão absoluta, é nos colocarmos não como donos da terra, mas como filhos dessa complexa trama. Norte e Sul são metáforas, por meio das quais se menciona a existência de modos de ser e estar distintos, distantes e divergentes em muitas situações e posicionamentos. Metáforas que nos recordam polos históricos de dominadores e dominados, ricos e pobres, alto consumo e sociedades carentes de condições mínimas, "culturas donde la abundancia lleva a desperdicios y culturas sumidas en la más flagrante miseria" (Noguera, 2007a, p. 7), como bem detalha Ángel Maya (2003) quanto à ambiguidade ambiental do desenvolvimento.

Considerando isso, Noguera ainda aponta o Sul não como ponto cardinal matematicamente preciso por linhas e graus, mas como modos de habitar outros, que implicam uma relação própria de um ethos Abya Yala. Como o Sul da geografia poética cartografado pelo pintor uruguaio Joaquín Torres García, em 1943, que inverte, inventa, rasura o padrão e nos incita ao geopensamento diverso e singular (Noguera \& Toro, 2016).

Nessa via, o Pensamento Ambiental Sul propõe um giro ambiental da cultura, do humano, da rede de símbolos que criou e alimenta a divisão homem/natureza, em um sonho de Frankenstein que, com remendos devasta a terra, industrializa a vida e arma a guerra de todos contra todos e contra todo. Entendendo as lógicas do sistema-mundo mas sem, todavia, generalizar tudo e todo espaço-tempo, a transformação profunda dos símbolos desta cultura do Norte, absolutamente contranatura, já encontra r-existências (Porto-Gonçalves, 2008) desde as muitas e várias comunidades que habitam esta Abya Yala em Bem viver. E "su propuesta que ya es la nuestra, consiste en la recuperación de maneras-otras de relacionarnos con aquella madre, la tierra, de la que emergió el humano, como humus, como aquel que la cuidaría", indica-nos Noguera $\&$ Toro (2016, p. 180).

A recuperação de maneiras outras de nos relacionarmos com a terra que nos humaniza fecunda uma geografia-Sul múltipla e transdisciplinar (Figura 3), possível de ser sentipensada apenas pela composição dos diversos ramos das ciências, filosofias, artes e saberes arraigados no cotidiano da vida que brota e floresce deste Sul.

A Figura 3 interliga alguns importantes conceitos-imagem em Noguera apontados ao longo de nosso texto. Longe de sintetizar toda a produção acadêmico-filosófica desta autora ainda bem ativa, compreendemos que geografia-Sul é a relação entranhada de modos múltiplos, generosos e coletivos de viver a terra que, em Noguera, tensiona e culmina num Pensamento Ambiental-Outro emergente da trama da vida expressos e impressos via geopoética e corpo-terra. O laço ético-estético-político-ambiental que compõe o Pensamento Ambiental por esta filósofa é transdisciplinar e em sutura, relevando a complexidade dos fenômenos e da necessidade de dissolver alguns pontos (dicotomias, essencialismos, universalismo) e de co-ligar outros (ecossistema-cultura, bio-sócio-diversidade, filosofia-geografia-história, corpo-terra). 


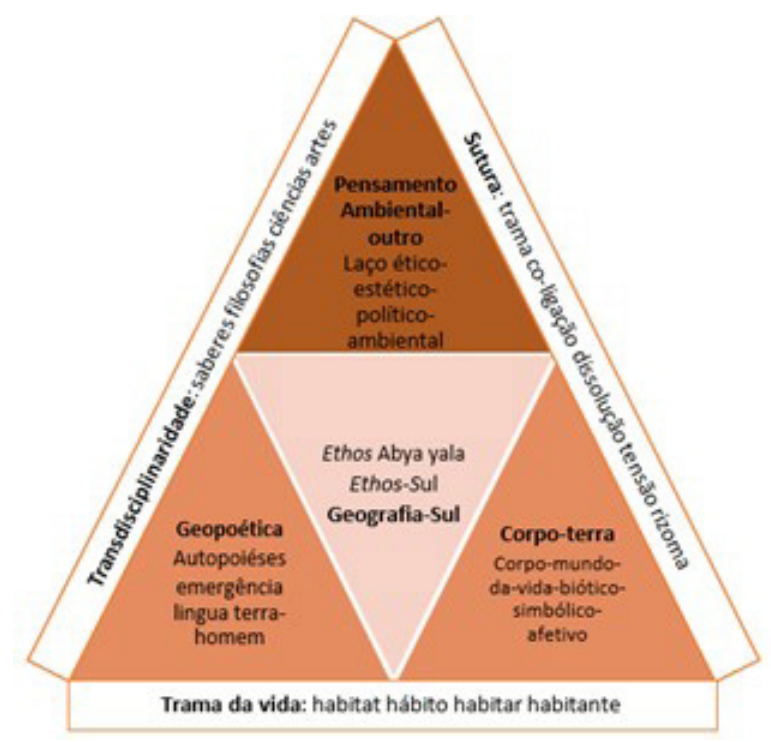

FIGURA 3 - Geografia-Sul: meio da realização do corpo-terra que somos.

\section{Considerações finais: desde o Sul e para além do Sul}

Inspirados pelos trabalhos da colombiana Ana Patricia Noguera de Echeverri, somos motivadas a pensar a relação entre os diversos ramos e campos das ciências, filosofias, artes e saberes, a partir do corpo-mundo-da-vida-simbólico-biótico-afetivo tecido na complexidade sistêmica da trama-rede que nos constitui.

Somos constituídos por, com e em terra, sendo a terra pensamento fecundo que nos habita e nos fertiliza em modos diversos de ser-estar. Este geopensamento em Noguera nos orienta para o descentramento do indivíduo e para a dissolução das oposições binárias sujeito $\mathrm{x}$ objeto, homem $\mathrm{x}$ natureza, cidade x campo, desenvolvidos x não desenvolvidos, entre outras dicotomias que se baseiam na razão predatória, dominadora e simplificadora da ciência moderna ocidental.

Aterrada pelo Pensamento Ambiental latino-americano, Noguera transborda uma geografia-Sul que emerge de nossa situação e circunstância. Um Sul não apenas em diferença a uma cultura do Norte, mas, sobretudo, um Sul que inverte, inventa, r-existe, transforma e habita as fissuras, os silêncios e as margens do discurso universalizante.

A filosofia ambiental por Ana Patricia Noguera invoca Husserl e o mundo da vida, Heidegger e o habitar, Spinoza e o multitudo, Deleuze e os rizomas, Fals Borda e o sentipensar, Pardo e a geopoética, entre outras matrizes, corroborando com um diálogo transdisciplinar que transpassa uma fenomenologia desde o Sul, pensando nossa existência a partir da realidade que aqui se funda, como emergência dos saberes destas terras. 
Enquanto marco epistêmico, o Sul em ciências, artes e filosofias é uma abertura afetuosa e atenta às nossas r-existências, às nossas ausências e emergências, ao nosso trato com a terra e com a vida em todas as suas dimensões.

Desde o Sul e para além do Sul, no pensamento em Noguera floresce as múltiplas experiências de Abya Yala e de um fazer científico-filosófico que regressa à casa, à terra, ao território-espaço-lugar, georreferenciando e cartografando a partir de nossos corpos enlaçados pela trama da vida.

Por florestas, chapadas, vales ou desertos; por etnias milenares preservadas, dizimadas ou reconstituídas; em pequenos grupos ou grandes cidades, uma geografia ao Sul é produzida em riqueza e diversidade nesta gigantesca América Latina que tanto carece de pensar-se, ouvir-se e propor-se científico-filosoficamente.

Sem esquecer-nos dos diversos tipos de explorações, guerras, domínios econômicos-políticos-culturais-pedagógicos, Noguera nos planta a semente de uma geografia-Sul em chave do reencantamento, capaz de pôr em relevo a poética em tempos de crise e penúria, via maneiras outras de habitar que nos constitui enquanto ethos Abya Yala, por uma geopoética de reconciliação do corpo-terra amputado pela razão moderna.

Nessa reconciliação, o giro epistêmico-estético-político-filosófico é uma urgência para pensar-se ambientalmente - algumas dessas maneiras de pensar são antigas e precisam ser re-ligadas, re-vividas, já outras são novas e ainda carecem de cuidados, adubo, semeadura, cultivo: "Emergen en las geografías-sur, configuradas en la tierra, por la tierra y de la tierra, maneras diferentes, antiguas unas, nuevas otras, de pensar la tierra que somos" (Noguera, 2014, p. 23).

\section{Agradecimentos}

À CAPES pela concessão de bolsa de doutorado à pesquisadora brasileira Elisabete Silva, e ao Ministério de Ciência e Tecnologia da Colômbia pelo apoio financeiro aos doutorandos no exterior/ convocatória 860 concedido à pesquisadora colombiana Diana Alexandra Bernal. Ao grupo NOMEAR, Fenomenologia e Geografia, sob orientação do Prof. Eduardo Marandola Jr, Unicamp/Limeira, que nos proporciona conhecer obras e autores tão preciosos.

\section{Referências}

Ángel Maya, A. El reto de la vida. Bogotá: Ecofondo, 1996. Ángel Maya, A. Hacia una sociedad ambiental. Bogotá: Editorial Labrador, 1990.

Ángel Maya, A. La diosa Nemesis: desarrollo sostenible o cambio cultural. Cali: Universidad Autónoma de Occidente, 2003.

Ángel Maya, A. La fragilidad ambiental de la cultura. Bogotá: Editorial Universidad Nacional/Instituto de Estudios Ambientales, 1995.

Bernal Arias, D. A. A rosa do deserto: hidropoéticas do lugar no habitar contemporâneo. Campinas, Dissertação (Mestrado em Geografia) - Unicamp, 2015.

Capra, F. La trama de la vida: una nueva perspectiva de los sistemas vivos. Barcelona: Anagrama, 1998.

Chacón, C. A. Pensamiento ambiental del maestro: ethos-Cuerpo en clave de Bio-Geo-Poéticas del Habitar. Cali/ Colômbia, Tese (doutorado em Educação) - Universidad del Valle, 2011. Disponível em: < bibliotecadigital.univalle. edu.co $>$

Escobar, A. Sentipensar con la tierra: nuevas lecturas sobre desarrollo, territorio y diferencia. Medellín: Ediciones UNAULA, 2014. 
Husserl, E. La crisis de las ciencias europeas y la fenomenología trascendental. Barcelona: Crítica, 1991.

Marandola Jr., E. Fenomenologia e pós-fenomenologia: alternâncias e projeções do fazer geográfico humanista na Geografia contemporânea. Geograficidade, 3(2), 49-54, 2013. doi: 10.22409/geograficidade2013.32.a12864

Merchancano-Benevides, O. D. Geopoéticas sur: paisaje Andino-Nariñense y educación ambiental. Geograficidade, 5 (especial), 126-150, 2015. doi: 10.22409/geograficidade 2015.50.a12933

Mesa, C. Superficies de contacto. Medellín: Mesa Editores, 2010.

Morin, E. El año I de la era ecológica: la tierra que depende del hombre que depende de la tierra. Barcelona: Paidós, 2008.

Morin, E. Introducción al Pensamiento Complejo. Barcelona: Ed. Gedisa, 1994.

Noguera, A. P. Banco de dados ColCiencias. Disponível em: <http://scienti.colciencias.gov.co:8085/gruplac/jsp/ visualiza/visualizagr.jsp?nro $=00000000000945>$. Acesso em: 14 maio 2018.

Noguera, A. P. Complejidad ambiental: propuestas éticas emergentes del pensamiento ambiental latinoamericano. Gestión y Ambiente, Bogotá, 10, 5-30, 2007a. Disponível em: <http://www.bdigital.unal.edu.co/13602/1/1156-66591-PB.pdf $>$

Noguera, A. P. Crisis ambiental: pérdida del cuerpo y de la tierra. Revista Cultura y Droga,17(19), 313-322, 2012a. Disponível em: <http://vip.ucaldas.edu.co/culturaydroga / downloads/Culturaydroga17(19)12.pdf $>$

Noguera, A. P. Cuerpo-tierra: el enigma, el habitar, la vida. potencias de un pensamiento ambiental en clave del reencantamiento del mundo. Madrid: Editorial Académica Española, 2012b.

Noguera, A. P. Cuerpo-tierra: ethos ambiental en clave de la lengua de la Tierra. Sustentabilidad(es), 2(1), 1-11, 2010. Disponível em: <http://www.sustentabilidades. usach.cl/ sites/sustentable/ files/paginas/02-10.pdf $>$

Noguera, A. P. Educación estética y complejidad ambien- tal. Manizales: Universidad Nacional de Colombia, 2000. Disponível em: $<$ https://enriquedussel.com/txt/Textos 200_Obras/Filosofia_ambiental/Educacion_estetica-Patricia_Noguera.pdf $>$. Acesso em: 15 jan. 2019.

Noguera, A. P. El paso del sujeto/objeto al bucle-red-trama-de vida disolución de la epistemología moderna y emergencia de la filosofía ambiental. In: Noguera, A. P. (Org.). Emergencias de un pensamiento ambiental alternativo en América Latina. Manizales: Universidad Nacional de Colombia, p. 15-52, 2007 b.

Noguera, A. P. El reencantamiento del mundo. Manizales: Programa de las Naciones Unidas para el Medio Ambiente-PNUMA/México, 2004.

Noguera, A. P. Escisión y reconciliación: movimiento autorreflextvo de la modernidade estética. Manizales: Universidad Nacional de Colombia, 1998.

Noguera, A. P. Paisajes del desarrollo: evocación, rememoración, conmemoración y reencantamiento. In: Noguera, A. P. (Org.). Voces del pensamiento ambiental: tensiones críticas entre desarrollo y Abya Yala. Manizales: Universidad Nacional de Colombia, p. 69-122, 2016.

Noguera, A. P. Pensamiento ambiental complejo y gestión del riesgo: una propuesta epistémico-ético-estética. Instituto de Estudios Ambientales, 1-30, 2006. Disponível em: $<$ http://idea.manizales.unal.edu.co/sitios/gestion_riesgos / descargas/gestion/ Propuestaepistemico.pdf $>$

Noguera, A. P. Pensamiento ambiental sur em tiempos de penuria. Cuadernos de Ética, 30, 1-22, 2015. Disponível em: $<$ http://aaieticas.org/revista/index.php/cde/article/ view/69>

Noguera, A. P.; Giraldo, O. ¿Para qué poetas en tiempos de extractivismo ambiental? In: Alimonda, H.; Toro, Catalina; Martín, Facundo (Orgs.). Ecología política latinoamericana: pensamiento crítico, diferencia latinoamericana y rearticulación epistémica. Ciudad Autónoma de Buenos Aires: CLACSO, p. 69-94, 2017.

Noguera, A. P.; Piñeda, J. Cuerpo-Tierra: epojé, disolución humano-naturaleza y nuevas geografias-sur. Geograficidade, 4(1), 20-29, 2014. doi: 10.22409/geograficidade 2014 $.41 . \mathrm{a} 12885$

Noguera, A. P.; Piñeda, J. Filosofía ambiental y fenomeno- 
logía: el paso del sujeto-objeto a la trama de vida en clave de la pregunta por el habitar poético contemporáneo. In: Actas del IV Coloquio Latinoamericano de Fenomenología. Morelia, México, p. 261 - 277, 29 de ago., 2009. Disponível em: <https://www.clafen.org/AFL/V3/261-277_Noguera. pdf>. Acesso em: 14 fev. 2019.

Noguera, A. P.; Piñeda, J. Medición del progreso de la sociedad. De las cuentas a los cuentos ambientales: propuesta de otra manera de pensarnos en clave de comunidad abyayalense en expansión vital. In: Rojas, M. (Org.). $L a$ medición del progreso y del bienestar: propuestas desde América Latina. México: Foro Consultivo Científico y Tecnológico, p. 285-296, 2011.

Noguera, A. P.; Piñeda, J. Rostros del Pensamiento Ambiental. Hacia una geopoética de la reconciliación. In: Alvarado, S. V. S; Alvarado, S, V,; Piñeda, J,; Tello, K, C, (Orgs,). Polifonías del sur: desplazamientos y desafíos de las ciencias sociales. Buenos Aires: CLACSO; Manizales: Universidad de Manizales; Bogotá: CINDE-Fundación Centro Internacional de Educación y Desarrollo Humano, p. $348-385,2017$.
Noguera, A. P.; Toro, C. Sí a la Vida: una propuesta emergente del Pensamiento Ambiental Sur. In: Nussbaum, M.; Rueda, E.; Gentili, P. (Org.). Paz en Colombia: perspectivas, desafíos, opciones. Ciudad Autónoma de Buenos Aires: CLACSO. p. 175-182, 2016.

Pardo, J. L. Sobre los espacios pintar, escribir, pensar. Barcelona: Ediciones del Serbal, 1991.

Piñeda, J. A. El acontecer de Ares: un mito entre el amor y la guerra. Geograficidade, 5 (especial), 36-49, 2015. doi: 10.22409/geograficidade2015.50.a12927

Porto-Gonçalves, C. W. De saberes e de territórios. In: Ceceña, A. C. (Org.). De los saberes de la emancipación y de la dominación. Buenos Aires: CLACSO, p. 37-52, 2008.

Serres, M. El contrato Natural. Paris: Pre-Textos, 1991. 